\title{
Изучение аминокислотного состава травы скабиозы бледно-желтой (Scabiosa ochroleuca L.) методом ВЭЖХ
}

\author{
Дроздова И.Л., Минакова Е.И. \\ ФГБОУ ВО «Курский государственный медииинский университет», Курск
}

Поступила в редакцию 7.11.2017 г.

В статье приведены результаты изучения аминокислотного состава травы скабиозы бледножелтой (Scabiosa ochroleuca L.) семейства ворсянковые (Dipsacaceae), полученные с помощью аминокислотного анализатора. Методом высокоэффективной жидкостной хроматографии (ВЭЖХ) установлено наличие 15 аминокислот, из них 7 - незаменимых (треонин, валин, метионин, изолейцин, лейцин, фенилаланин, лизин). Аминокислотный состав исследуемого растения изучен впервые.

Ключевые слова: скабиоза бледно-желтая, Scabiosa ochroleuca L., аминокислотный состав, высокоэффективная жидкостная хроматография (ВЭЖХ).

\section{The study of amino acid composition of herb Scabiosa ochroleuca L. by HPLC}

\author{
Drozdova I.L., Minakova E.I. \\ Kursk State Medical University, Kursk
}

\begin{abstract}
Purpose of work was to analyze the amino acid composition of the herb Scabiosa ochroleuca L. family Dipsacaceae by high performance liquid chromatography (HPLC). The object of the study was air-dried chopped herb Scabiosa ochroleuca L., harvested in the flowering phase. The presence of amino acids set qualitative reactions. To study the content of amino acids was applied the method of high performance liquid chromatography (HPLC). The contents of amino acids were determined using amino acid analyzer (Amino Acid Analyzer AAA 400).

Qualitative reactions proved the presence of amino acids. By HPLC revealed the existence of 15 amino acids (12 aliphatic; 1 heterocyclic and 2 aromatic amino acids, which is consistent with the literature data on the content of amino acids in plants). 7 acids are essential (threonine, valine, methionine, isoleucine, leucine, phenylalanine, lysine). The content of amino acids makes up 4,94\%, including essential amino acids of $1,66 \%$. At present the predominant concentration of glutamic acid $(0,63 \%)$. The amino acid composition of the investigated plants was studied for the first time. The results indicate the prospects of using plants as a source of amino acids. In combination with other groups of biologically active substances (phenolic compounds, polysaccharides, macro - and microelements and other) it emphasizes the therapeutic importance of herbs Scabiosa ochroleuca L. and enables the development of new affordable domestic medicines combined action on the basis of promising species of medicinal plants.
\end{abstract}

Keywords: Scabiosa ochroleuca L., amino acid composition, high performance liquid chromatography (HPLC).

\section{Введение}

В настоящее время в России для лечения и профилактики различных заболеваний применяется более 6,5 тысяч лекарственных средств растительного происхо- 
ждения. Это связано с тем, что препараты на растительной основе обладают малой токсичностью и широким спектром терапевтического действия, обусловленного комплексом биологически активных веществ (БАВ). Одним из классов БАВ растений являются аминокислоты. На основе аминокислот современной мировой фармацевтической промышленностью выпускается целый ряд препаратов: Аминовен, Аминосол-Нео, Нутрифлекс, Мориамин С-2, Ноопепт, Глицин, Метионин, АлькаПрим и другие [1].

Источником аминокислот могут служить лекарственные растения. Широкое распространение аминокислот в растениях и их высокая биологическая активность способствуют эффективному действию на организм лекарственного сырья и полученных из него препаратов [2]. Однако до настоящего времени состав аминокислот многих растений отечественной флоры не изучен, что в современных условиях импортозамещения является актуальным.

Одними из таких растений являются представители рода Скабиоза (Scabiosa L.) семейства ворсянковые (Dipsacaceae). Род насчитывает около 100 видов, преимущественно распространенных в Средиземноморье. Во флоре России произрастает 16 видов, из которых наиболее распространена скабиоза бледно-желтая (Scabiosa ochroleuca L.) - двулетнее или многолетнее травянистое растение [3-6]. На территории Центрально-Черноземного района данный вид распространен повсеместно, имеет значительную сырьевую базу [5]. Встречается на склонах, полянах, опушках, лугах, среди кустарников $[3,4,6]$.

Скабиоза бледно-желтая в настоящее время применяется только в народной медицине в качестве ранозаживляющего средства, при геморрое, заболеваниях кожи (при кожных сыпях и бородавках), глаз, женских болезнях. Экспериментальными исследованиями установлено, что тритерпеноиды травы скабиозы бледно-желтой вызывают лизис злокачественных опухолей, водно-спиртовая настойка семян проявляет антиамебную активность, полифенольный комплекс обладает антиоксидантными свойствами $[3,6]$.

Из данных литературы известно, что трава содержит различные фенольные соединения, а именно: флавоноиды (кверцетин, кверцимеритрин, диосмин, охрозид, гликозиды лютеолина) [6], (виценин, гисперидин, апигенин, гиперозид, рутин, робинин, кверцетин [7], фенолкарбоновые кислоты (кофейная, хлорогеновая, галловая, цикориевая, феруловая) [6,7], кумарины (дигидрокумарин) и дубильные вещества [7], а также углеводы, макро- и микроэлементы [7]. Подземная часть растения содержит тритерпеновые сапонины [3]. Однако такой класс БАВ как аминокислоты до настоящего времени в траве скабиозы бледно-желтой не изучался.

Учитывая широкий спектр биологической активности аминокислот, их способность улучшать биодоступность и потенцировать эффект других классов БАВ, цель нашей работы заключалась в анализе состава аминокислот травы скабиозы бледно-желтой методом высокоэффективной жидкостной хроматографии (ВЭЖХ).

\section{Эксперимент}

Объектом исследования служила воздушно-сухая измельченная трава скабиозы бледно-желтой. Сырье заготавливалось в Курской области в период массового цветения растений. Для изучения состава аминокислот в траве скабиозы бледножелтой использовали метод высокоэффективной жидкостной хроматографии (ВЭЖХ), который является наиболее распространенным современным методом аналитической химии, применяется в разнообразных областях анализа (включая определение БАВ). Данный метод в настоящее время широко используется для качест- 
венного и количественного анализа лекарственного растительного сырья преимущество которого - возможность автоматизации процесса контроля [8] и рассматривается как один из самых чувствительных и точных методов анализа, обеспечивающих высокую селективность определения и позволяющих разделить смесь веществ на составляющие компоненты, что особенно важно при получении и исследовании биологически активных веществ [9].

Предварительное качественное обнаружение аминокислот проводили в водных извлечениях с помощью нингидриновой реакции. Для этого 5.0 г воздушносухого измельченного сырья заливали $50 \mathrm{~cm}^{3}$ воды очищенной и нагревали с обратным холодильником на кипящей водяной бане в течение 1 часа. Извлечение фильтровали, сырье заливали снова $50 \mathrm{~cm}^{3}$ воды и операцию повторяли. Водные извлечения, полученные после трехкратной экстракции, объединяли, упаривали под вакуумом до $25 \mathrm{~cm}^{3}$ и использовали для проведения качественных реакций. При качественном анализе смешивали равные объемы исследуемого извлечения и $0.1 \%$ свежеприготовленного раствора нингидрина и осторожно нагревали. При охлаждении развивалось красно-фиолетовое окрашивание, что указывает на присутствие аминокислот в исследуемом растении [10-12].

Для изучения содержания аминокислот применяли аминокислотный анализатор (Amino Acid Analyzer AAA 400, Чехия) - узкоспециализированный автоматизированный жидкостный хроматограф с компьютерным управлением, оснащенный постколоночной детекторной системой. Для анализа аминокислот 0.2 г образца сырья (точная навеска) помещали в специальные ампулы, добавляли $20 \mathrm{~cm}^{3}$ раствора кислоты хлористоводородной (6 моль/дм³ $)$, ампулы запаивали и проводили гидролиз в сушильном шкафу в течение 23 часов при температуре $110^{\circ} \mathrm{C}$. После гидролиза ампулы охлаждали до комнатной температуры, извлечение фильтровали и выпаривали досуха в ротационном испарителе, добавляли $5 \mathrm{~cm}^{3}$ воды и снова выпаривали, операцию повторяли 2 раза. Сухой остаток растворяли в $50 \mathrm{~cm}^{3}$ загрузочного натриевоцитратного буфера (pH 2.2). Анализ аминокислот проводили на аминокислотном анализаторе в стандартных условиях (ступенчатый градиент, скорость потока буферных растворов $0.3 \mathrm{~cm}^{3} /$ мин, скорость потока нингидринового реактива $0.2 \mathrm{~cm}^{3} /$ мин, детектирование в УФ областях 440 и 570 нм, температура термостата реактора $121^{\circ} \mathrm{C}$ ). Заданные количества стандартного и испытуемого растворов через дозировочную петлю $\left(0.1 \mathrm{~cm}^{3}\right)$ вводили в колонку аминокислотного анализатора. Для количественной оценки использовали площади пиков идентифицированных аминокислот, рассчитанные прибором [12,13].

\section{Обсуждение результатов}

Результаты исследования аминокислотного состава травы скабиозы бледножелтой методом ВЭЖХ представлены в таблице 1 . Из данных таблицы 1 видно, что трава скабиозы бледно-желтой содержит 15 аминокислот, из которых 7 являются незаменимыми (треонин, валин, метионин, изолейцин, лейцин, фенилаланин, лизин). По мере убывания содержания в исследуемом лекарственном сырье все обнаруженные аминокислоты можно расположить в виде следующего ряда: Glu $>$ Arg $>$ Phe $>$ Ala $>$ Leu $>$ Gly $>$ Tyr $>$ His $>$ Ser $>$ Asp $>$ Thr $>$ Lys $>$ Val $>$ Ile $>$ Met.

Установлено, что среди идентифицированных аминокислот большинство (12 соединений) относятся к группе алифатических; также установлено наличие 1 гетероциклической и 2 ароматических аминокислот, что согласуется с литературными данными о содержании аминокислот в растениях [10-15]. Алифатические кислоты представлены 8 моноаминомонокарбоновыми кислотами (глицин, аланин, валин, 
изолейцин, лейцин), в т.ч. содержащими оксигруппу (треонин, серин) и серусодержащими (метионин) соединениями. Моноаминодикарбоновые кислоты представлены аспарагиновой и глутаминовой кислотами, диаминомонокарбоновые кислоты лизином и аргинином. Из ароматических аминокислот в траве скабиозы бледножелтой обнаружены тирозин и фенилаланин. Гетероциклические кислоты представлены гистидином.

Таблица 1 Результаты исследования аминокислотного состава травы скабиозы бледно-желтой методом ВЭЖХ

\begin{tabular}{|c|c|c|}
\hline №/П & Аминокислота & $\begin{array}{c}\text { Содержание, \% в пересчете на абсолютно } \\
\text { сухое сырье }\end{array}$ \\
\hline \multicolumn{3}{|c|}{ Алифатические кислоты } \\
\hline \multicolumn{3}{|c|}{ - моноаминомонокарбоновые кислоть } \\
\hline 1 & Треонин *(Thr) & 0.25 \\
\hline 2 & Серин(Ser) & 0.33 \\
\hline 3 & Глицин (Gly) & 0.38 \\
\hline 4 & Аланин(Ala) & 0.43 \\
\hline 5 & Валин*(Val) & 0.16 \\
\hline 6 & Метионин* (Met) & 0.05 \\
\hline 7 & Изолейцин* (lle) & 0.10 \\
\hline 8 & Лейцин*(Leu) & 0.39 \\
\hline \multicolumn{3}{|c|}{ - моноаминодикарбоновые кислоты } \\
\hline 9 & Аспарагиноваякислота (Asp) & 0.30 \\
\hline 10 & Глутаминовая кислота $(\mathrm{Glu})$ & 0.63 \\
\hline \multicolumn{3}{|c|}{ - диаминомонокарбоновые кислоты } \\
\hline 11 & Лизин*(Lys) & 0.22 \\
\hline 12 & Аргинин (Arg) & 0.51 \\
\hline \multicolumn{3}{|c|}{ Ароматические кислоты } \\
\hline 13 & Тирозин(Туг) & 0.36 \\
\hline 14 & Фенилаланин*(Phe) & 0.49 \\
\hline \multicolumn{3}{|c|}{ Гетероциклические кислоты } \\
\hline 15 & Гистидин (His) & 0.34 \\
\hline
\end{tabular}

Примечание: «*» - незаменимые аминокислоты

Преобладающей аминокислотой в траве скабиозы бледно-желтой является алифатическая глутаминовая кислота $(0.63 \%)$, относящаяся к группе нейромедиаторных аминокислот, стимулирующих передачу возбуждения в синапсах ЦНС. Важная роль данной аминокислоты заключается в том, что она участвует в углеводном, белковом обмене, окислительных процессах, способствует синтезу АТФ, переносу ионов калия, увеличивает резистентность организма к гипоксии. В медицинской практике ее используют при лечении различных заболеваний ЦНС (эпилепсии, психозов, депрессии, в детской практике - при задержке психического развития, ДЦП, болезни Дауна, полиомиелите) [16]. Кроме глутаминовой кислоты, для нормальной работы мозга и ЦНС необходимы глицин и тирозин, которые обнаружены в исследуемом виде в значительных количествах (0.38\% и $0.36 \%$ соответственно). Высокое содержание в траве исследуемого вида скабиозы отмечено также для таких аминокислот как аргинин $(0.51 \%)$, аланин $(0.43 \%)$, лейцин $(0.39 \%)$, которые наиболее часто входят в состав ноотропных лекарственных средств [16]. Содержание аминокислот в пересчете на абсолютно сухое сырье составляет в исследуемом виде $4.94 \%$, в т.ч. незаменимых аминокислот $1.66 \%$ (что является достаточно высоким показателем для растений), среди которых преобладает фенилаланин (0.49\%). 


\section{Заключение}

Таким образом, использование метода высокоэффективной жидкостной хроматографии (ВЭЖХ) позволило установить, что трава скабиозы бледно-желтой содержит 15 аминокислот, в т.ч. 7 - незаменимых. Преобладающей аминокислотой в исследуемом растении является глутаминовая кислота. Среди незаменимых аминокислот преобладает фенилаланин.

В комплексе с другими группами БАВ (фенольными соединениями, полисахаридами, макро- и микроэлементами и другими) это подчеркивает терапевтическую значимость травы скабиозы бледно-желтой и дает возможность разработки новых доступных отечественных препаратов комбинированного действия на основе перспективного вида лекарственного растительного сырья. Аминокислотный состав исследуемого растения изучен впервые.

\section{Список литературы}

1. Государственный реестр лекарственных средств. Режим доступа: http://www.grls.rosminzdrav.ru (дата обращения 17.05.2017)

2. Кхалед Абу Захер, Журавлев Н.С. // Электронный журнал «Провизор». 2001. № 21. http://www.provisor.com.ua/

3. Дикорастущие полезные растения России. / Отв. ред. А.Л. Буданцев, Е.Е. Лесиовская. СПб. Изд-во СПХФА. 2001. 663 с.

4. Маевский П.Ф. Флора средней полосы Европейской части России. М. Товарищество научных изданий КМК. 2006. 600 с.

5. Прудников Н.А., Полуянов А.В. Сосудистые растения Курской области. Курск: КГУ. 2005. 80 с.

6. Растительные ресурсы России: Дикорастущие цветковые растения, их компонентный состав и биологичексая акивность. T.4. Семейства Caprifoliaceae-Lobeliaceae / Отв. ред. А.Л. Буданцев. М. Товарищество научных изданий КМК. 2011. 630 с.

7. Крупенникова В.Г. Фармакогностическое исследование Scabiosa comosa и Scabiosa ochroleuca L., произрастающих в Восточной Сибири. Автореф. дис. канд. фарм. наук, Улан-Удэ, 2007. 15 c.

8. Сергунова Е.В., Сорокина А.А. // Фармачия. 2012. № 5. С. 11-13.

\section{References}

1. Gosudarstvennyi reestr lekarstvennykh sredstv. Rezhim dostupa: http://www.grls.rosminzdrav.ru (data obrashcheniya 17.05.2017)
9. Мироненко Н.В., Брежнева Т.А., Михина И.А., Селеменев В.Ф. // Заводская лаборатория. Диагностика материалов. 2009. T. 75. № 5. C. 19-23.

10. Тринеева О.В., Синкевич А.В., Сливкин А.И. // Химия растительного сырья. 2015. № 2. С. 141-148.

11. Киселева Т.Л., Люй Г., Чаузова А.В. // Традищионная медищина. 2014. № 1 (36). С. 49-52.

12. Дроздова И.Л., Денисова Н.Н. // Традищионная медищина. 2012. № 4 (31). С. 4951.

13. Дроздова И.Л., Лупилина Т.И. // Вестник Воронежского государственного университета. Серия: Химия. Биология. Фармаичия. 2015. № 1. С. 125-128.

14. Тринеева О.В., Синкевич А.В., Сливкин А.И., Сафонова Е.Ф. // Сорбционные и хроматографические проиессы. 2014. Т. 14. № 3. С. 530-536.

15. Тринеева О.В., Сливкин А.И., Дмитриева А.В. // Разработка и регистрация лекарственных средств. 2014. № 9. С. 136142.

16. Шилова И.В., Кувачёва Н.В., Самылина И.А. // Фармация. 2016. Т. 65. № 4. С. 3538.

2. Kkhaled Abu Zakher, Zhuravlev N.S. Aminokislotnyi sostav nekotorykh vidov rastenii roda Rumex L. // Elektronnyi zhurnal «Provizor». $\quad$ №21. 2001. http://www.provisor.com.ua/ 
3. Dikorastushchie poleznye rasteniya Rossii. I Otv. red. A.L. Budantsev, E.E. Lesiovskaya, SPb., Izd-vo SPKhFA, 2001, 663 p.

4. Maevskii P.F. Flora srednei polosy Evropeiskoi chasti Rossii, M., Tovarishchestvo nauchnykh izdanii KMK, 2006, 600 p.

5. Prudnikov N.A., Poluyanov A.V., Sosudistye rasteniya Kurskoi oblasti, Kursk, KGU, 2005, 80 p.

6. Rastitel'nye resursy Rossii: Dikorastushchie tsvetkovye rasteniya, ikh komponentnyi sostav i biologicheksaya akivnost'. T.4. Semeistva Caprifoliaceae-Lobeliaceae / Otv. red. A.L. Budantsev, SPb.; M., Tovarishchestvo nauchnykh izdanii KMK, 2011, 630 p.

7. Krupennikova V.G. Farmakognosticheskoe issledovanie Scabiosa comosa i Scabiosa ochroleuca L., proizrastayushchikh v Vostochnoi Sibiri. Avtoref. dis. kand. farm. nauk, Ulan-Ude, 2007, 15 p.

8. Sergunova E.V., Sorokina A.A.,, Farmatsiya, 2012, No 5, pp. 11-13.

9. Mironenko N.V., Brezhneva T.A., Mikhina I.A., Selemenev V.F., Zavodskaya labora-

Дроздова Ирина Леонидовна - д.фарм.н., декан фармацевтического и биотехнологического факультетов, профессор кафедры фармакогнозии и ботаники ФГБОУ ВО «Курский государственный медицинский университет» Минздрава России, Курск

Минакова Евгения Игоревна - студент фармацевтического факультета ФГБОУ ВО «Курский государственный медицинский университет» Минздрава России, Курск toriya. Diagnostika materialov, 2009, Vol. 75, No 5, pp. 19-23.

10. Trineeva O.V., Sinkevich A.V., Slivkin A.I., Khimiya rastitel'nogo syr'ya, 2015, No 2, pp. 141-148.

11. Kiseleva T.L., Lyui G., Chauzova A.V., Traditsionnaya meditsina, 2014, No 1 (36), pp. 49-52.

12. Drozdova I.L., Denisova N.N., Traditsionnaya meditsina, 2012, No 4 (31), pp. 49-51.

13. Drozdova I.L., Lupilina T.I., Vestnik Voronezhskogo gosudarstvennogo universiteta. Seriya: Khimiya. Biologiya. Farmatsiya, 2015, No 1, pp. 125-128.

14. Trineeva O.V., Sinkevich A.V., Slivkin A.I., Safonova E.F., Sorbtsionnye i khromatograficheskie protsessy, 2014, Vol. 14, No 3, pp. 530-536.

15. Trineeva O.V., Slivkin A.I., Dmitrieva A.V., Razrabotka i registratsiya lekarstvennykh sredstv, 2014, No 9, pp. 136-142.

16. Shilova I.V., Kuvacheva N.V., Samylina I.A., Farmatsiya, 2016, Vol. 65, No 4, pp. 3538.

Drozdova Irina L. - the doctor of pharmaceutical Sciences, the Dean of the pharmaceutical and biotechnological faculties, Professor of the Department of pharmacognosy and botany of the Kursk state medical University, Kursk, E-mail: irina-drozdova@yandex.ru

Minakova Eugenia I. - student of pharmaceutical faculty of the Kursk state medical University, Kursk 